JIKAP PGSD: Jurnal Ilmiah Ilmu Kependidikan

Vol,3. No,1. Tahun 2019

e-ISSN: 2597-4440 dan p-ISSN: 2597-4424

This work is licensed under a Creative Commons Attribution

4.0 International License

\title{
Profil Sarana Dan Prasarana Pengajaran Pendidikan Jasmani Di Sekolah Dasar Negeri Kec. Tanete Riattang Barat Kabupaten Bone
}

\author{
Muliadi \\ Fakultas Ilmu Pendidikan UNM \\ Email: muliadi6452@unm.ac.id
}

\begin{abstract}
Abstrak: Penelitian ini bertujuan mendeskripsikan kondisi obyektif profil sarana dan prasarana pengajaran pendidikan jasmani di SD Negeri Kec.Tanete Riattang Barat Kab.Bone. Metode penelitian ini meggunakan rancangan deskriptif. Pengumpulan data dilakukan dengan teknik angket, dekumentasi dan observasi. Analisis data yang digunakan adalah deskriptif kuantitatif. Dari hasil penelitian ini diperoleh yaitu: (a) Lapangan tempat bermain ada 100\%, (b) Lapangan Voli ada 25\%, dan (c) Lapangan lompat jauh ada 33,33\%. Berkaitan dengan alat-alat pendidikan jasmani: (a) 91,66 \% mempunyai bola kecil, (b) $33,33 \%$ mempunyai bola sepak, (c) 16,66 \% mempunyai bola tangan, (d)75\% mempunyai bola voli, (e) 8,33\% mempunyai bola basket, (f) 41,66 \% mempunyai alat lompat tinggi, (g) $16,66 \%$ mempunyai matras, (h) $33,33 \%$ mempunyai tongkat estafet, (i) 41,66 \% mempunyai net voli, (j) 16,66\% mempunyai tali tambang, (k) tidak ada yang memiliki balok keseimbangan, (l) tidak ada yang memiliki palang tunggal, dan (m) tidak ada yang memiliki tiang ring basket. Sedang rasio untuk penggunaan alat-alat pendidikan jasmani adalah: (a) Untuk bola kecil rasio yang mempunyai frekuensi paling banyak dalam menggunakan bola untuk 30 siswa dengan lima bola adalah 8,33\%, (b) Untuk bola sepak rasio yang mempunyai frekuensi paling banyak dengan satu bola adalah $25 \%$, (c) Untuk bola tangan rasio yang mempunyai frekuensi paling banyak dengan satu bola adalah 16,66 \%, (d) Untuk bola voli rasio yang mempunyai frekuensi paling banyak dengan satu bola adalah $75 \%$, dan (e) Untuk bola basket rasio yang mempunyai frekuensi paling banyak dengan satu bola adalah 8,33 \% .
\end{abstract}

Kata kunci: Sarana, Prasarana, Pendidikan jasmani

Abstract: This study aims to describe the objective conditions of the profile of facilities and infrastructure for teaching physical education in the State Elementary School of Kec. Tanete Riattang Barat, Kab. This research method uses descriptive design. Data collection is done by questionnaire techniques, documentation and observation. The data analysis used is descriptive quantitative. The results of this study are: (a) the playing field is $100 \%$, (b) the Volleyball court is $25 \%$, and (c) the long jump field is $33.33 \%$. Regarding physical education tools: (a) $91.66 \%$ have small balls, (b) $33.33 \%$ have soccer balls, (c) $16.66 \%$ have handballs, (d) $75 \%$ have volleyball, (e) $8.33 \%$ have basketball, (f) $41.66 \%$ have a high jump tool, (g) $16.66 \%$ have a mat, (h) $33.33 \%$ have a baton, (i) $41.66 \%$ has a net volley, (j) $16.66 \%$ has a rope, $(\mathrm{k})$ no one has a balance beam, (l) no one has a single crossbar, and (m) no one has a basketball hoop. While the ratio for the use of physical education tools is: (a) For small balls the ratio that has the most frequency in using the ball for 30 students with five balls is $8.33 \%$, (b) For soccer balls the ratio has the most frequency with one ball is $25 \%$, (c) For hand balls the ratio that has the most frequency with one ball is $16.66 \%$, (d) For volleyball the ratio that 
has the most frequency with one ball is $75 \%$, and (e ) For basketball the ratio that has the most frequency with one ball is $8.33 \%$.

Keywords: Facilities, Infrastructure, Physical Education

\section{PENDAHULUAN}

Dalam dunia pendidikan dan pengajaran telah diketahui bahwa setiap bidang studi memiliki ciri-ciri khusus dalam penyampaiannya. Berbagai bentuk pengajaran bidang studi akan tercermin dalam kegiatan belajar mengajarnya. Demikian juga halnya dengan bidang studi pendidikan jasmani. Kuriulum SD tahun 1994 telah meletakkan perinsip-perinsip dasar dan fungsi kegiatan pendidikan jasmani. Dalam kurikulum tersebut dikemukakan bahwa kegiatan pendidikan jasmani di sekolah berdasarkan Pancasila dan Undang-Undang Dasar 1945. Pernyataan itu sejalan dengan bunyi UndangUndang Tentang Sistem Pendidikan Nasional Nomor 2 Tahun 1989 (1989 : 51) berikut ini: “ Pendidikan Nasional adalah pendidikan yang berakar pada kebudayaan bangsa Indonesia dan berdasarkan pada Pancasila dan Undang-Undang Dasar 1945 “.

Bertolak dari kutipan di atas dapat diambil suatu pengertian bahwa salah satu fungsi utama pendidikan jasmani di sekolah adalah membentuk manusia pembangun yang berdasarkan Pancasila. Pengertian ini sesuai dengan tujuan pendidikan Nasional, seperti yang tercantum dalam UndangUndang Tentang Sistem Pendidikan Nasional Nomor 2 Tahun 1989 (1989) yang berbunyi Pendidikan Nasional bertujuan mencerdaskan kehidupan bangsa dan mengembangkan manusia Indonesia seutuhnya, yaitu manusia yang beriman dan bertaqwa terhadap Tuhan Yang Maha Esa dan berbudi luhur, memiliki pengetahuan dan keterampilan, kesehatan jasmani dan rohani, kepribadian yang mantap dan mandiri serta tanggungjawab kemasyrakatan dan kebangsaan.

Selain fungsi tersebut di atas, pendidikan jasmani di sekolah berfungsi juga sebagai alat pendidikan, yaitu untuk meningkatkan pertumbuhan dan perkembangan tubuh, meningkatkan kesegaran jasmani, meningkatkan kesehatan, meningkatkan ketangkasan dan keterampilan, pengetahuan dan kecerdasan serta menanamkan kehidupan yang kreatif, rekreatif dan sosial. Oleh karena itu tugas seorang guru pendidikan jasmani cukup berat, karena dalam pelaksanaannya meliputi pertumbuhan dan perkembangan secara fisik maupun mental. Dikatakan demikian karena kalau seorang guru pendidikan jasmani salah memberikan konsep dasar gerak, maka akan berakibat fatal bagi siswa itu.

Dalam upaya memenuhi tuntutan kurikulum 1994 tersebut, maka keberadaan sarana dan prasarana tidak kalah pentingnya dengan aspek-aspek pengajaran lainnya. Dalam praktek pengajaran sering dijumpai, bagaimanapun pandainya guru dalam menyampaikan materi kepada siswanya, akan tetapi kalau tidak didukung oleh sarana dan prasarana yang memadai, maka mustahil pengajaran tersebut dapat berhasil sesuai dengan yang diharapkan. Sesuai dengan pentingnya sarana dan prasarana ini, Ndong Kamtomo (1986 : 32) menegaskan "Faktor alat perlengkapan dan fasilitas yang semula tidak mendatangkan problema-problema khusus, dengan adanya kemajuan-kemajuan pelaksanaan teknis pada saat sekarang ini, ternyata juga ikut memegang peranan yang menentukan terhadap keberhasilan suatu team atau individu dalam pencapaian prestasi yang tinggi “. Penegasan Kamtomo di atas tentunya berlaku semua jenis pengajaran. Khusus di bidang pengajaran pendidikan jasmani alat-alat yang dimaksudkan adalah alat-alat yang dapat menunjang pelaksanaan pokok-pokok bahasan yang terdapat dalam kurikulum pendidikan jasmani di sekolah dasar tahun 1994.

Adapun menurut kurikulum sekolah dasar alat dan peralatan yang diperlukan adalah sebagai berikut :a) Matras/kasur-kasuran dari terpal/karung 1 × 2 meter, b) Tali untuk perorangan dan beregu, c) Macam-macam bola : Bola kasti, Bola tenis bekas, Bola tangan,Bola sepak, bola karet, Bola voli, Bola basket,

Tongkat lari sambung, e) Balok/papan keseimbangan, f) Palang tunggal, g) Net voli, g) Gelang /ring basket dan tiang basket, dan h) Tambang.

Di samping alat-alat penunjang di atas, juga diperlukan fasilitas lain seperti : Lapangan untuk atletik, lapangan untuk sepak bola, lapangan basket, serta lapangan voli yang memadai. Memang diakui bahwa penyediaan alat dan fasilitas pendidikan yang memadai, khususnya untuk pengajaran pendidikan jasmani akan menimbulkan sikap positif terhadap kegiatan-kegiatan yang dilakukan. Hal ini tentu akan menambah gairah belajar siswa. Pernyataan ini sejalan dengan pendapat Winarno Surakhmat 
(1980 : 25) bahwa " Penggunaan alat-alat dalam proses belajar mengajar bertujuan mempertinggi prestasi belajar pada umumnya ". Dengan demikian terang pula bahwa guru harus mempunyai pengertian akan fungsi dan kedudukan alat-alat di dalam pekerjaannya sehari-hari .

Menurut Soenardi Soemosasmito (1988: 120) Unsur utama dalam pelajaran yang efektif adalah usaha guru untuk melibatkan siswa secara tepat terhadap suatu mata pelajaran, dengan presentase keterlibatan siswa yang tinggi dari waktu yang tersedia, dengan mempertimbangkan strategi mengajar yang mendukung terciptanya suasana belajar yang akrab dan ramah .

Disisi lain, guru pendidikan jasmani juga berfungsi/bertugas mendidik dan membimbing siswa. Karena itu untuk dapat menjalankan tugasnya dengan baik maka guru pendidikan jasmani harus : a)Mempunyai rasa kasih sayang, b)Mempunyai kelebihan keadaan jasmaninya, sikap perwujudannya, daya tarik tersendiri dan tentang pengetahuannya, c)Berwibawah, d)Mengetahui dan mempertimbangkan perbedaan karakteristik fisik dan psikologi siswa, baik putra maupun putri.

Sedangkan menurut Degeng (1990: 2) menegaskan "Saat ini diperlukan pengetahuan tentang jenis-jenis metode yang dapat membuat belajar menjadi lebih mudah dan lebih menyenangkan bagi siswa; metode yang lebih efektif, efesien dan memiliki daya tarik tinggi" Bertolak dari uraian-uraian sebelumnya dapat ditegaskan :a) Adanya keterkaiatan antara usaha guru, penggunaan metode, serta adanya alat-alat yang memadai akan menunjang keberhasilan kegiatan belajar mengajar sesuai dengan tuntutan kurikulum b)Tersedianya alat-alat yang cukup memadai akan menambah semangat serta gairah bagi guru-guru pendidikan jasmani untuk melaksanakan tugasnya c)Tersedianya alat-alat pendidikan jasmani yang cukup memadai akan membuat siswa semakin bergairah dalam berlatih dan memacu keinginannya untuk meningkatkan kemampuannya.

\section{METODE PENELITIAN}

Penelitian ini bersifat deskriptif, yaitu untuk mengungkapkan atau mendeskripsikan kondisi obyektif profil sarana dan prasarana pengajaran pendidikan jasmani di Sekolah Dasar Negeri Kecamatan Tanete Riattang Barat Kabupatan Bone.
Metode penelitian dirancang melalui langkah-langkah penelitian dari mulai operasionalisasi variabel, penentuan jenis dan sumber data, metode pengumpulan data atau survei, model penelitian diakhiri dengan merancang analisis data dan pengujian hipotesis. Dalam melakukan penelitian dibutuhkan adanya suatu metode, cara atau taktik sebagai langkahlangkah yang harus ditempuh oleh seorang peneliti dalam memecahkan suatu permasalahan untuk mencapai suatu tujuan. Adapun metode yang penulis gunakan dalam penelitian adalah metode deskriptif kuantitatif.

Menurut Sugiyono (2009 : 5) pengertian dari metode penelitian adalah sebagai berikut :

"Metode penelitian dapat diartikan sebagai cara ilmiah untuk mendapatkan data yang valid dengan tujuan dapat ditemukan, dikembangkan, dan dibuktikan, suatu pengetahuan tertentu sehingga pada gilirannya dapat digunakan untuk memahami, memecahkan dan mengantisispasi masalah".

Dengan metode ini penulis bermaksud mengumpulkan data historis dan mengamati secara saksama mengenai aspek-aspek tertentu yang berkaitan dengan masalah yang sedang diteliti oleh penulis sehingga akan memperoleh data-data yang dapat mendukung penyusunan laporan penelitian. Data-data yang diperoleh tersebut kemudian diproses dan dianalisi lebih lanjut dengan dasar teori yang telah dipelajari sehingga memperoleh gambaran mengenai objek tersebut dan dapat ditarik kesimpulan mengenai masalah yang diteliti.

maka metode penelitian yang digunakan adalah metode deskriptif dengan teknik total sampling untuk menentukan sampel. Pengumpulan data dilakukan dengan teknik angket, dekumenter dan observasi. Analisis data yang digunakan adalah deskriptif kuantitatif.

Instrumen penelitian adalah suatu alat yang digunakan untuk mengumpulkan data dalam sebuah penelitian. Penelitian ini pada dasarnya adalah melakukan pengukuran terhadap fenomena-fenomena sosial, maka dalam penelitian ini harus ada alat yang tepat. Adapun instrumen yang digunakan dalam penelitian ini adalah :

1. Instrumen yang digunakan adalah dengan menggunakan observasi, wawancara, dan kuesioner metode tertutup, dimana kemungkinan pilihan jawaban sudah ditentukan terlebih dahulu dan responden tidak diberikan alternatif jawaban lain. 
2. Indikator - Indikator untuk kedua variabel tersebut kemudian dijabarkan oleh penulis menjadi sejumlah pernyataan sehingga diperoleh data kualitatif. Data ini akan dianalisis dengan pendekatan kuantitatif menggunakan analisis statistik. Sedangkan teknik ukuran yang digunakan yaitu teknik Skala Likert atau skala sikap. Pengertian Skala Likert menurut Sugiyono (2009:93) adalah, "Skala Likert digunakan untuk mengukur sikap, pendapat, dan persepsi seseorang atau sekelompok orang tentang fenomena sosial."Dalam skala sikap ini, responden menyatakan persetujuannya dan ketidaksetujuannya terhadap sejumlah pernyataan yang berhubungan dengan obyek yang di teliti.

Teknik pengumpulan data merupakan cara-cara yang dilakukan untuk memperoleh data dan keterangan-keterangan yang diperlukan dalam penelitian. Teknik pengumpulan data yang dilakukan, yaitu Penelitian Lapangan (Field Research).

Penelitian lapangan adalah penelitian yang dimaksudkan untuk memperoleh data primer yaitu data yang diperoleh melalui :

a. Pengamatan (Observation)

b. Wawancara (Interview)

c. Kuesioner (Questionaire)

Populasi penelitian menurut Sugiyono (2009: 117), adalah wilayah generalisasi yang terdiri atas objek atau subjek yang mempunyai kualitas dan karakteristik tertentu yang ditetapkan oleh peneliti untuk dipelajari dan

kemudian ditarik kesimpulan. Populasi dalam penelitian ini adalah seluruh Sekolah Dasar Negeri Kec. Tanete Riattang Barat Kab. Bone, adapun sampel dalam penelitian ini adalah menggunakan sampel jenuh dalam artian seluruh populasi adalah merukan sampel.

Menganalisis data merupakan satu langkah yang sangat kritis dalampenelitian. Data yang diperoleh perlu diolah lebih lanjut agar dapat memberikan keterangan yang dapat dipahami. Metode yang digunakan untuk menganalisis data dalam penelitian ini adalah metode statistik deskriptif. Analisis data statistik sesuai dengan data kuantitatif atau data yang dikuantifikasikan, yaitu data dalam bentuk bilangan, sedang data deskriptif hanya dianalisis menurut isinya (Suryabrata, 2003:40). Analisis deskriptif bertujuan untuk memberikan deskripsi mengenai subjek penelitian berdasarkan data dari variabel yang diperoleh dari kelompok subjek yang diteliti dan tidak dimaksudkan untuk pengujian hipotesis (Azwar, 2001:126). Data yang telah terkumpul kemudian diklasifikasikan menjadi dua kelompok data, yaitu data kuantitatif yang berbentuk angka-angka dan data kualitatif yang dinyatakan dalam kata-kata atau simbol. Data yang diperoleh dijumlahkan atau dikelompokkan sesuai dengan bentuk instrumen yang digunakan (Arikunto, 2006:240). Agar data dapat terbaca dan dapat dipahami maka perlu dilengkapi dengan kata-kata yang dapat memberi gambaran yang jelas mengenai kondisi sarana dan prasaran olahraga yang dimiliki sekolah.

\section{HASIL DAN PEMBAHASAN}

Berdasarkan hasil pengolahan data penelitian diperoleh bahwa keadaan sarana dan prasarana untuk kegiatan pendidikan jasmani di Sekolah Dasar Negeri Kecamatan Tanete Riattang Kabupaten Bone, masih belum memadai sesuai dengan tututan kurikulum terutama yang berkaitan dengan Alat-alat untuk kegiatan pendidikan jasmani dan Rasio penggunaan alatalat pendidikan jasmani, hal itu terlihat pada paparan berikut ini:

Alat-alat pendidikan jasmani: (a) 91,66\% mempunyai bola kecil, (b) 33,33\% mempunyai bola sepak, c) 16,66 \% mempunyai bola tangan, (d)75\% mempunyai bola voli, (e) $8,33 \%$ mempunyai bola basket, (f) $41,66 \%$ mempunyai alat lompat tinggi, (g) 16,66\% mempunyai matras, (h) 33,33\% mempunyai tongkat estafet, (i) $41,66 \%$ mempunyai net voli, (j) 16,66\% mempunyai tali tambang, (k) tidak ada yang memiliki balok keseimbangan (l) tidak ada yang memiliki palang tunggal, dan (m) tidak ada yang memiliki tiang ring basket.

Sedang rasio untuk penggunaan alat-alat pendidikan jasmani adalah: (a) Untuk bola kecil rasio yang mempunyai frekuensi paling banyak dalam menggunakan bola untuk 30 siswa dengan lima bola adalah $8,33 \%$, (b) Untuk bola sepak rasio yang mempunyai frekuensi paling banyak dengan satu bola adalah $25 \%$,(c) Untuk bola tangan rasio yang mempunyai frekuensi paling banyak dengan satu bola adalah 16,66 \%, (d) Untuk bola voli rasio yang mempunyai frekuensi paling banyak dengan satu bola adalah $75 \%$, dan (e) Untuk bola basket rasio yang mempunyai frekuensi paling banyak dengan satu bola adalah $8,33 \%$.

Lapangan untuk tempat melakukan kegiatan pendidikan jasmani (bermain) dapat dikatakan sudah memenuhi tuntutan kurikulum, hal itu didasarkan atas prosentase yaitu bahwa semua sekolah (100\%) mempunyai tempat 
bermain atau tempat melakukan kegiatan pendidikan jasmani, Lapangan Voli ada di 3 SD (25\%), dan Lapangan untuk lompat jauh ada di 4 SD $(33,33 \%)$.

Dengan demikian dapat dikatakan bahwa lapangan bermain masih memenuhi tuntutan kurikulum, akan tetapi untuk alat-alat pengajaran pendidikan jasmani serta rasio penggunaan alat masih sangat kurang.

\section{SIMPULAN DAN SARAN}

Dari proses dan hasil analisis penelitian ini dapat disimpulkan bahwa keadaan sarana dan prasarana untuk kegiatan pengajaran pendidikan jasmani di Sekolah Dasar Negeri Kec.Tanete Riattang Barat Kab. Bone, masih belum memadai sesuai dengan tuntutan kurikulum, terutama yang berkaitan dengan Alat-alat untuk kegiatan pendidikan jasmani serta rasio penggunaan Alatalat pendidikan jasmani. Namun demikian lapangan untuk tempat melakukan kegiatan pendidikan jasmani (bermain) dapat dikatakan sudah memenuhi tuntutan kurikulum, hal itu didasarkan atas prosentase yaitu semua sekolah $(100 \%)$ mempunyai tempat bermain atau tempat melakukan kegiatan pendidikan jasmani, sejumlah 3 sekolah ( $25 \%$ ) mempunyai lapangan Voli, sejumlah 4 sekolah $(33,33 \%)$ mempunyai lapangan lomat jauh. Akhirnya penelitian ini menyarankan bahwa Guru pendidikan jasmani hendaknya lebih kreatif untuk dapat menanggulangi kekurangan alat-alat dengan memodifikasi alat-alat yang ada, sehingga proses belajar mengajar tetap dapat berlangsung dengan wajar.

Guru pendidikan jasmani dengan dibantu siswa dapat membuat alat-alat yang sederhana untuk dapat digunakan di dalam kegiatan proses belajar mengajar.

Nampaknya masih perlu dilakukan penelitian lanjutan sehubungan dengan sarana dan prasarana dengan memperluas populasi atau sampel penelitian dan masalah yang diteliti. Dengan demikian tidak hanya terbatas pada sekolah dasar, akan tetapi juga melibatkan SLTP ataupun SLTA . Perluasan sampel dan masalah penelitian dimaksudkan agar hasil penelitian ini lebih valid dan memiliki daya generalisasi yang lebih luas, sehingga hasilnya benar-benar dapat digunakan sebagai bahan masukan atau wawasan dalam merencanakan dan mengembangkan pengajaran pendidikan jasmani yang lebih baik dimasa mendatang.

\section{DAFTAR RUJUKAN}

Azwar, Saifuddin. 2001. Metode Penelitian. Yogyakarta : Pustaka Pelajar.

Depdikbud. 1994. Kurikulum 1994 Sekolah Dasar, Olahraga Dan Kesehatan . Jakarta.

Kamtomo, Ndong. 1986. Psikologi Olahraga. Jakarta : PT.Plagan.

Sudana, Degeng. 1990. Pengembangan Landasan Ilmiah Dan Teknologis Upaya Perbaikan Kualitas Pengajaran, Majalah Pendidikan Fakultas Ilmu Pendidikan IKIP Malang, Edisi 1990 No. 23 Th.XVII.

Sugiyono. 2000. Statistika untuk Penelitian. Bandung : Alfabeta

Surakhmad, Winarno. 1980. Pengantar Interaksi Belajar Mengajar Dasar dan Teknik Metodologi Pengajaran. Bandung : Tarsito Bandung.

Suryabrata, Sumadi. 2006. Metodologi Penelitian. Jakarta : Raja Grafindo Persada

Soemosasmito, Soenardi. 1988. Dasar Proses Dan Efektifitas Belajar Mengajar Pendidikan Jasmani. Jakarta : Proyek Pengembangan Lembaga Pendidikan Tenaga Kependidikan , 1989. Undang-Undang Republik

Indonesia No. 2 Tahun 1989 Sistem Pendidikan Nasional. Jakarta : Armas Duta Jaya. 